Pak. j. sci. ind. res. Ser. B: biol. sci. 2021 64B(2) 116-125

\title{
Green Synthesis of Dyes and Appliance on Silk by Using Metamordating Technique
}

\author{
Bushra Shamsheer*, Tahira Aziz Mughal, Zubaida Yousaf, Hamna Yasin, \\ Nadia Riaz, Arusa Aftab and Maria Zahoor \\ Department of Botany, Lahore College for Women University, Lahore, Pakistan
}

(received May 5, 2018; revised September 2, 2019; accepted November 14, 2019)

\begin{abstract}
The main idea of extracting dyes from plant (natural) sources is to avoid the environmental pollution. Natural dye from plants has been given much interest in recent years due to the threat and harmful effects are used by synthetic dyes and environmental awareness created by researchers. The drawback of synthetic dyes is that they are not durable as they do not completely fix on all kind of fabric and remaining dyestuff drained into rivers, becoming the cause of water pollution as well as they cause diseases in human being like cancer and allergies. On the other hand, natural dyes are eco-friendly and find use in the colouring of textiles, drugs and cosmetics etc. Owing to their non-toxic effects, they are also even used for colouring various food products. Mordents are used in natural dyes which enhance the colour of dye and stick it on fabric. Due to lack of availability of precise technical knowledge on the extracting and dyeing technique, it has not commercially succeeded like the synthetic dyes. Hence, the present study was planned to isolate eco-friendly dyes from the bark of the plants (Ziziphus jujube Mill., Albizialebbeck L., Cordia dichotoma G. Forst., Ficus benghalensis L. and Cassia fistula L.) and the roots of Ficus benghalensis L. Later on the dyes were applied on silk fabric by using metamordating technique. Then fastness properties like rubbing, heating, washing and sunlight were evaluated by using gray scale. F. benghalensis showed excellent fastness properties. Z. jujube showed series of colour variations on silk. Therefore, the bark and root of these plants can be successfully used for dyeing of silk. Natural dyes worldwide should be increased to prevent us from pollution and other harmful effects.
\end{abstract}

Keywords: natural dye, plants, eco-friendly, metamordant technique, silk fabric, bark, textile

\section{Introduction}

The art of dying is as old as our civilization (Kumar and Prabha, 2018). Before the discovery of synthetic dyes by William Henry Perkin in 1856, dyes obtained from plants were in use all over the world (Fan et al., 2018). Dyed textile remnants found during archaeological ex-cavations at different places all over the world provide evidence to the practice of dying in ancient civilizations. Natural dyes were used only for the colouring of textiles from ancient times till the nineteenth century (Kumar and Prabha, 2018). Afterward, synthetic dyes with low cost, plentiful colours, and easy access gradually replaced natural plant dyes. Nowadays, with increasing realization that some synthetic dyes can be harmful to health and the environment (Plácido et al., 2016; Shadeera, 2015; Mujadžiæ et al., 2014) there is renewed interest in natural dyeyielding plants (Shakeri et al., 2018). Furthermore, due to the severe threat of ecological globalization, environmental degradation and cultural homogenization, it is crucial to record the indigenous knowledge of plant *Author for correspondence; E-mail: bushrakhan_1234@yahoo.com utilization and preserve the plants' habitats, especially where they are not yet completely lost (Geng et al., 2016).

In the recent years synthetic dyes are totally being avoided to use because of environmental hazards (Bechtold et al., 2009; Samanta and Agarwal, 2009; Vankar et al., 2007). The European Union recently banned the use of azo dyes because of its harmful effects (Sivakuma et al., 2011). Many countries have eluded use of azo dyes in the textile industry. But the need of dyes in fabric industry is going to increase day by day so, there is a need to find out suitable and less toxic alternative sources of synthetic dyes (Paitoon et al., 2002). One such product from nature is the dye. Previously, pigment from leaves, fruits, seed, wood and roots were used as dye stuff for textiles and as paint in art and craft. Natural dyes are environmental friendly, hygienic, user friendly and permanent than other colourant. The replacement of natural dyes could happen until the introduction of synthetic dyes due to feasible colouring property of natural dyes (Kumaresan et al., 2011). 
Certain problems with the use of natural dyes in textile dyeing are colour yield, complexity of dying process, reproducibility results, limited shades, blending problems and inadequate fastness properties (Sachan and Kapoor, 2007; Siva, 2007). But these problems can be overcome by using chemicals called as mordants. Mordants are metal salts which produce an affinity between the fabric and the dye (Samanta and Agarwal, 2009; Vankar et al., 2009). One of the pleasures of using natural dye is that no baths will ever give exactly the same result, there will be an element of surprise with variation accordingly to the season, the weather, the maturity of the plant, its position in the sun or shade and the quality of the water used for dyeing will determine the dyeing quality (DivyaLekshmi and Ravi, 2013).

The dyers are trying to use natural dyes on regular basis both at small and larger scale to avoid environmental hazards caused by synthetic dyes. Natural dyes have no toxic effects. Therefore, it can be used in food products for colouration (Sivakuma et al., 2011). They have great tendency to bind with fabric. So, these dyes make a broad range of colours by using different plants part and apply on fabric like wool and cotton (Allen et al., 2008). They produce rare, peaceful and malleable colours unlike synthetic dyes (Allen and Bain, 2008).

Silk is composed of proteinous material which comes in contact with the body provide a suitable environment for the growth of pathogens and produce offensive smell and numerous diseases like dermal infections, product deterioration and allergies (Khan et al., 2011). As well as synthetic dyes used for dyeing silk are harmful for the mammalian cells and cause liver tumor. So, the demand of natural dyes is raised after knowing its therapeutic properties like it is antifungal, non-carcinogenic and antimicrobial (Chenghiah et al., 2011). Antimicrobial activity of Turmeric terminalli dye was checked and it was conclude that natural dyes were bound tightly with fabric and give good antimicrobial activity against fungal pathogens (Ranjit and Kalirajan, 2012).

Aqueous extract of Hibiscus mutabilis (cotton rose) flowers gave different shades of green colour with different mordents. These colours have been applied on silk fabric at commercial level. But the extraction from flower is difficult and only green colour range is produced. Mangrove bark is also used to form natural dyes because it has tannin. These dyes were applied on silk and gave only reddish-brown colour with different mordents (Nattaya et al., 2013). In the present work five plants species extracts were used to dye the silk fabrics at optimized conditions byusing a four mordant and checked the colour fastness of the dyed fabrics were also evaluated. The aim of this study was to isolate the natural dyes from the bark and root of plant species, to find the uses of different type of mordants and to check the effect of dyes on silk fabric by using meta mordating technique.

\section{Material and Methods}

For the extraction of dyes, green synthesis is preferable because this method is easy to perform, harmless and eco-friendly. The dyes used in this method are more reliable, consistent, give bright colour range and show different effect in the presence of different mordants. Following steps were used to perform this method:

Collection of plants. Fresh bark of the tree of Ziziphus jujube Mill., Albizialebbeck L., Cordiadichotoma G. Forst., Ficus benghalensis L. and Cassia fistula L. were collected from Pakistan Council of Scientific and Industrial Research (PCSIR) Laboratories Complex, Lahore, Pakistan, in November. Voucher specimens were submitted in Herbarium of Lahore College for Women University, Lahore, Pakistan.

Processing of plant material. All the selected part of the plants were weighed and washed to remove the dust particle. After sun drying material was used for extraction of dye.

Extraction of dye. The water was used as solvent for extraction. The plant material and water was mix in the ration of 1:100 w/v. Then, it was boiled on water bath approximately for 6-8 $\mathrm{h}$ until the final volume of aqueous extracts was reached upto $500 \mathrm{~mL}$. The solution was filtered and stored at $4{ }^{\circ} \mathrm{C}$ in the refrigerator for further processing.

Dyeing of silk. Dyeing is the process to colour the textile fiber. The colouring substance should be the vital part of the fabric rather than an outer coating. The ratio of fabric and aqueous extract 1:20 w/v was used. Before dyeing silk fabric was dipped in water for $24 \mathrm{~h}$. The required temperature for dyeing of silk was 100 ${ }^{\circ} \mathrm{C}$ for $1 \mathrm{~h}$ for complete dyeing.

Dyeing without mordant. For this purpose, $10 \mathrm{~g}$ piece of silk was dipped in the beaker containing $200 \mathrm{~mL}$ aqueous extract. Then boiled on water bath for $1 \mathrm{~h}$ at $100{ }^{\circ} \mathrm{C}$ with continuous stirring. Afterward the piece of silk was rinsed and colour was noted. 
Dyeing with mordants. A mordant is a substance, used to stick the dyes on fabric to produce different colours from the same extract. It can be added before and after or during process of dyeing. Metamordating technique was used for dyeing of silk. Different mordant like potash alum, copper sulphate, ferrous sulphate and potassium per magnate were used in the present study to develop different colours from a same extraction. Wet fabric ( $10 \mathrm{~g})$ was dipped in 200 aqueous dyes and boiled on water bath at $100{ }^{\circ} \mathrm{C}$ for $45 \mathrm{~min}$. Then $0.2 \mathrm{~g}$ mordant was added in and further boiled for $15 \mathrm{~min}$. The fabric was thoroughly rinsed, washed, squeezed and dried at room temperature.

Verification of colour fastness properties. It was evaluated by following parameters:

Washing. The transfer of colour from silk to wool and cotton was analyzed by using washing technique.

Colour fastness to washing. Dyed silk fabric, wool and cotton were cut into $4 \times 10 \mathrm{~cm}$ size pieces and sewed with each other in such a way that their faces were adjacent to each other. Took the 1:50 w/v ration of fabric and soap solution in the beaker then put on water bath at $80{ }^{\circ} \mathrm{C}$ for $30 \mathrm{~min}$. Rinsed the fabric, checked the change in colour. Change in colour of specimen and staining of adjacent fabrics was assessed with the help of grey scale.

Colour fastness to dry and wet rubbing. The colour fastness of silk against drying and wet rubbing was evaluated with help of Crockmeter instrument. Silk fabrics of $5 \times 14 \mathrm{~cm}$ were fixed firmly by clamps to base board of Crockmeter. The piece of silk was first rubbed in dry condition and then in wet condition. Rubbing was done by to and fro motion in a straight line along a pathway of $10 \mathrm{~cm}$ long on exterior of fabrics 10 times in $10 \mathrm{sec}$ with descending force on the finger rubbing. Fabrics were dried at $25^{\circ} \mathrm{C}$. Change in shade of the dyed fabrics and staining of the rubbing cloth was evaluated with the help of grey scale.

Colour fastness to light. Weather meter instrument was used to evaluate the colour fastness to light. Weather meter is made by Atlas according to ISO 105 set method B02, in which the source of artificial light was Xenon arc lamp, representative of natural day light D65. Silk fabrics of size $7 \times 12 \mathrm{~cm}$ were exposed to D65 light and result of colour fastness were determined with help of grey scale.
Colour fastness to heat. Hand iron was used to check the colour fastness against dry heating on silk fabric. At specific temperature fabric was pressed for 5-10 min. Then change was noted by using grey scale.

\section{Results and Discussion}

Bark of Z. jujube, A. lebbeck, C. dichotomy, F. benghalensis and $C$. fistula was used for silk dyeing. Root of $F$. benghalensis was also used for extraction of natural dye. Fixation of dye was done by four different mordants $\left(\mathrm{CuSO}_{4}, \mathrm{KMnO}_{4}, \mathrm{FeSO}_{4}\right.$ and Pot-Alum). Bark and root extraction with four different mordants resulted in production of 30 different shades. Fastness properties of all extracted dyes range between good and excellent (Fig. 1-5). The colour obtained from bark of Z. jujube extract was reddish. Five shades of this colour were produced with or without using different mordants. Pink with $\mathrm{CuSO}_{4}$ dark blue with $\mathrm{FeSO}_{4}$, dark brown with $\mathrm{KMnO}_{4}$ and Pot were produce. Alum gave grayish brown shade (Table 1). The fastness properties like washing, rubbing, heating and light of these five shade ranged from 3.5-4 (Fig. 1). A. lebbeck extract was reddish brown. Different mordents gave different colours. Brown with $\mathrm{CuSO}_{4}$, blue with $\mathrm{FeSO}_{4}$, with $\mathrm{KMnO}_{4}$ dark brown and Pot. Alum gave light brown colour (Table 1). Fastness properties like washing, rubbing, heating and light of these five shades ranged from 3-4 (Fig. 2). C. dichotoma extract was light brown. Different shades of brown were obtained with and without mordants (Table 1). Fastness properties like washing, rubbing, heating and light ranged from 3.5-4 (Fig. 3). The bark of $F$. benghalensis extract was red and with mordants gave bright colours while the root extract was brown in colour and with mordants gave dark shades (Table 1). The fastness properties like washing, rubbing, heating and light of $F$. benghalensis was in the range of 4-5 (Fig. 4). C. fistula extract was reddish brown and with mordants different shades of brown were obtained. The fastness properties like washing, rubbing, heating and light of C. fistulawas in the range of 4-5 (Fig. 5).

Clothing is one of the basic needs of human beings. Silk fabric and other textile material contain moisture, nutrients and suitable temperature for the growth of microbes. So, there is a need to dye the fabric with material which prevents it from microbial attack (Singh et al., 2005). Natural dyes retard the growth of microorganisms without producing toxicity (Han and Yang, 2005). Synthetic dyes are also useful to prevent the fabric from the microbial attack but synthetic dyes cause 
Table 1. Silk colour variation of Z. jujuba, A. lebbeck, C. dichotoma, F. benghalensis (Bark and Root) in aqueous extract

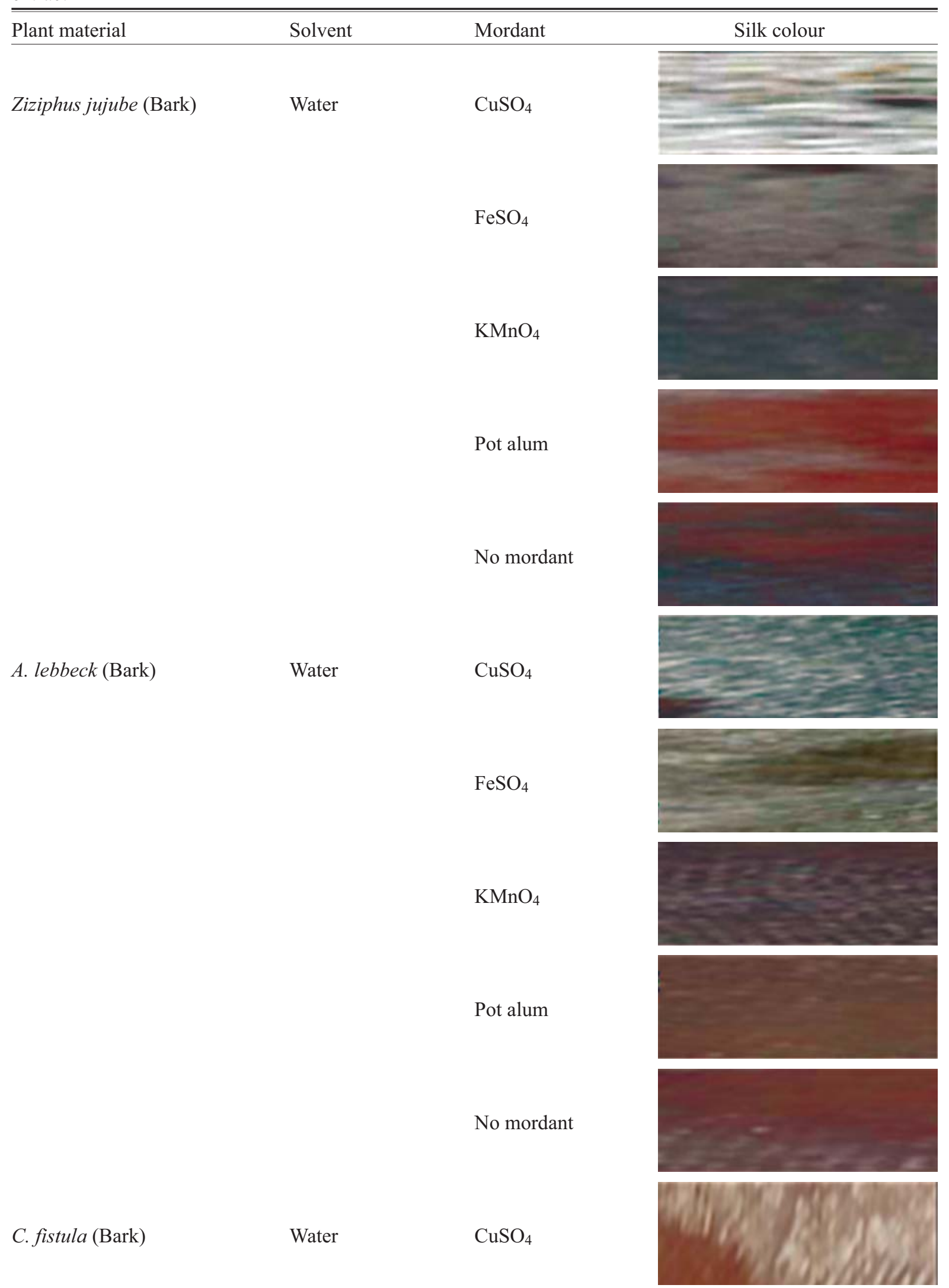


$\mathrm{FeSO}_{4}$

$\mathrm{KMnO}_{4}$

Pot alum

No mordant

C. dichotoma (Bark)

Water
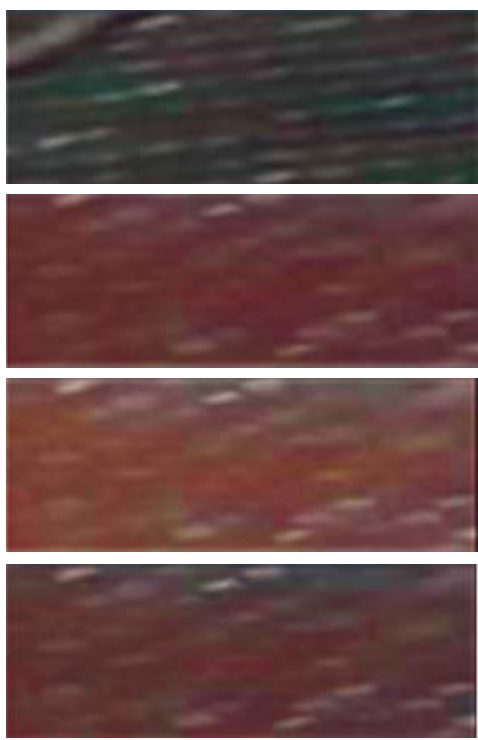

$\mathrm{FeSO}_{4}$

$\mathrm{KMnO}_{4}$

Pot alum
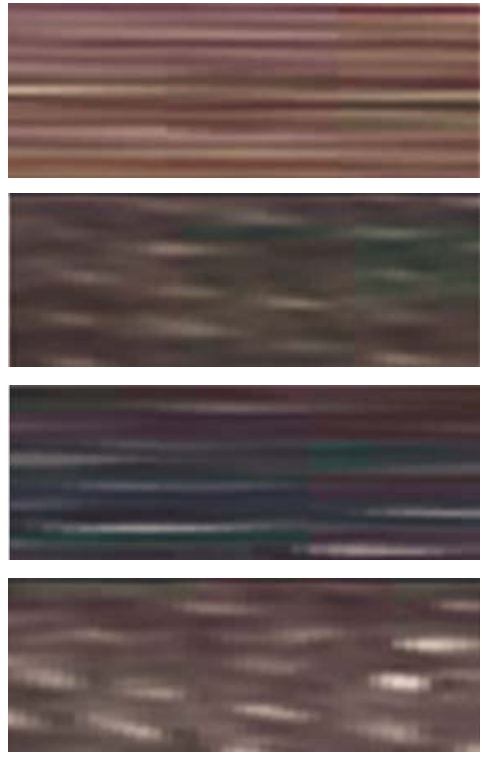

No mordant

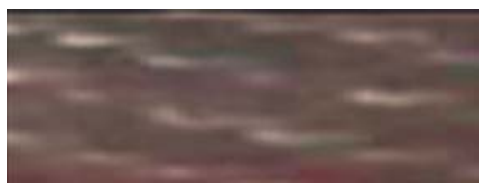

F. benghalensis (Bark)

Water

$\mathrm{CuSO}_{4}$

$\mathrm{FeSO}_{4}$

$\mathrm{KMnO}_{4}$
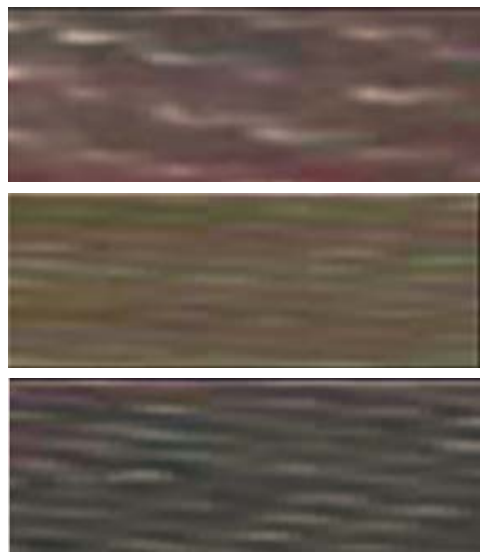
Pot alum

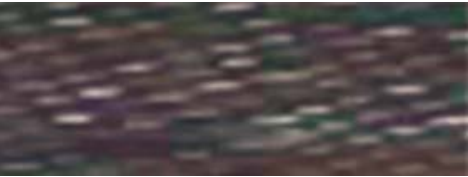

No mordant

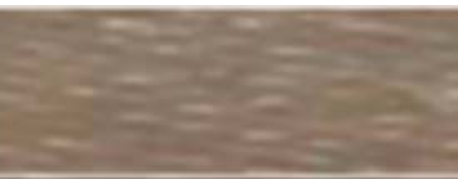

F. benghalensis (Root)

Water

$\mathrm{CuSO}_{4}$

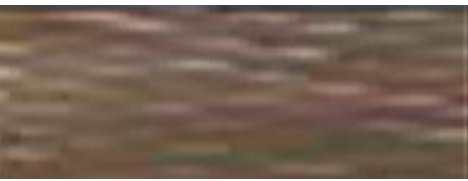

$\mathrm{FeSO}_{4}$

$\mathrm{KMnO}_{4}$

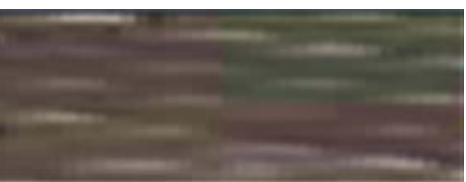

Pot alum
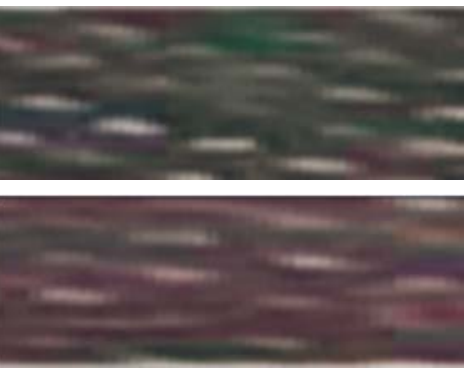

No mordant

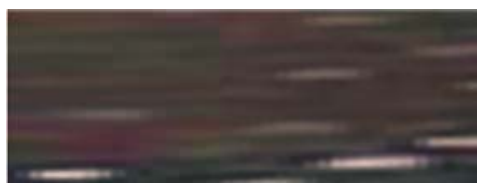

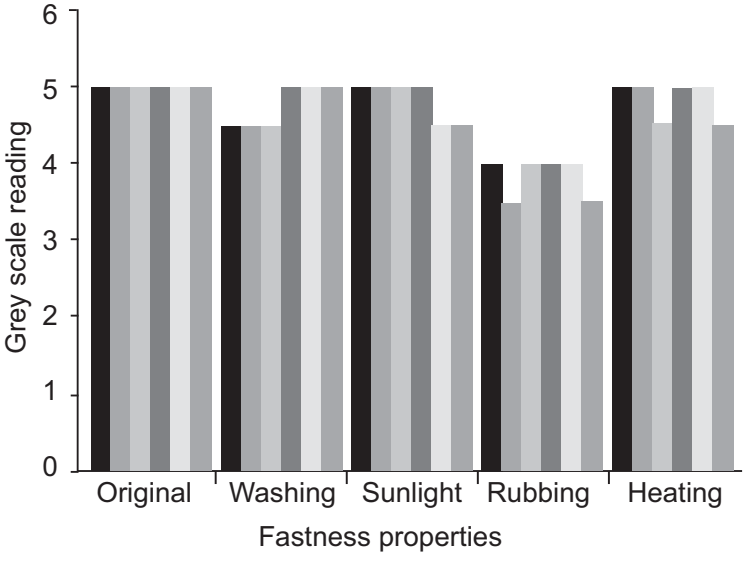

Z. jujube $\square$ A. lebbeck $\square$ C. dichotoma $\square$ F. benghalensis F. benghalensis2 $\square$ C. fistula

Fig. 1. Fastness properties of $Z$. jujube, A. lebbeck, C. dichotomy, F. benghalensis, $F$. benghalensis(2) and C. fistula without mordant.

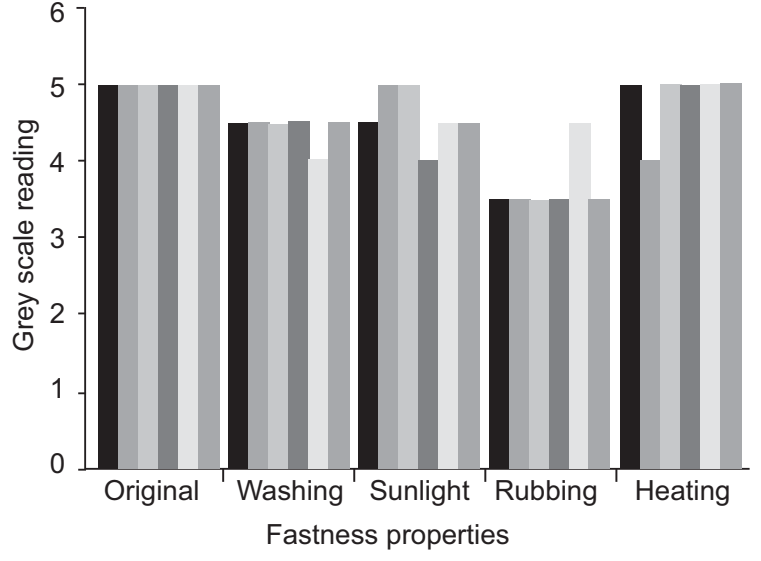

Z. jujube $\square$. lebbeck $\square$ C. dichotoma $\square$ F. benghalensis F. benghalensis2 $\square$ C. fistula

Fig. 2. Fastness properties of $Z$. jujube, A. lebbeck, C. dichotomy, F. benghalensis, $F$. benghalensis(2) and C. fistulawith $\mathrm{CuSO}_{4}$ mordant. 
environmental pollution (Singh et al., 2005). In 1856 the first synthetic dyes were introduced. These dyes are widely used for dyeing of different types of clothes like leather, cotton, wool and silk fabrics but they are not eco-friendly and harmful for environment as well as for human beings. According to the United States EPA 5 to 35 gallons of water is required to dye fabric. Fibre absorbed the dye from solution this is called fixation rate. Fixation rate is not $100 \%$ so, remaining dyed solution is drained into river. The textile industry annually discharges 40,000 to 50,000 tons of dye into rivers and approximately 200,000 tons of salt which polluted the water.

To overcome these hazards plants extract are used for dyeing purpose because these dyes are eco-friendly, bio-degradable and harmless (Mongkholrattanasit et al., 2007). Many companies produced and supply natural dyes. De la Robbia in Milan produced natural dyes for textile industries under Eco-Tec system. Allegro natural dyes in USA also produced and supply natural dyes under E-colour label system (Hwang et al., 2008).

Characteristically, natural dyes have been reported manifold advantages. They have wide variety, noncarcinogenic, non-poisonous, bio-degradable and nonhazardous to life (Thiyagarajan et al., 2015; Saravanan et al., 2014). Unlike synthetic dyes, the natural dyes are renewable, non-toxic, sustainable and well known to create soft, subtle, pastel, soothing (Pervaiz et al.,

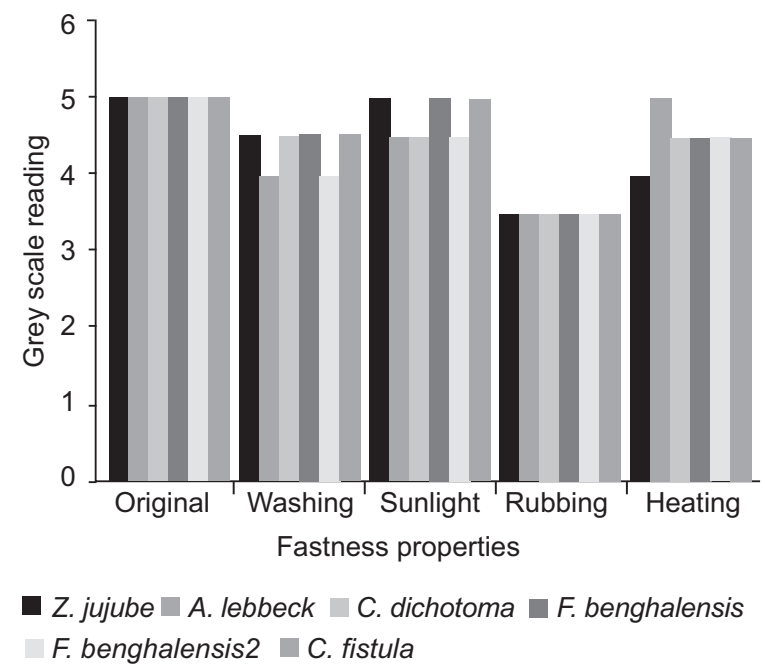

Fig. 3. Fastness properties of $Z$. jujube, A. lebbeck, C. dichotomy, F. benghalensis, $F$. benghalensis(2) and C. fistula with $\mathrm{FeSO}_{4}$ mordant.
2016; Kulkarni et al., 2011; Samantaa and Agarwal, 2009; Onal et al., 2005) and vibrant colours (Srivastava and Gautam, 2014). Natural dyes are neither harmful for human beings nor hazardous for environment (Shahid and Muhammad, 2013). Plant based dyes are reported economical (Pervaiz et al., $2016 \mathrm{a}, \mathrm{b}$ and c; Jadhao and Rathod, 2013), and easy to handle, render fragrance in the dyed substrate (Pervaiz et al., 2016 a, b and c),

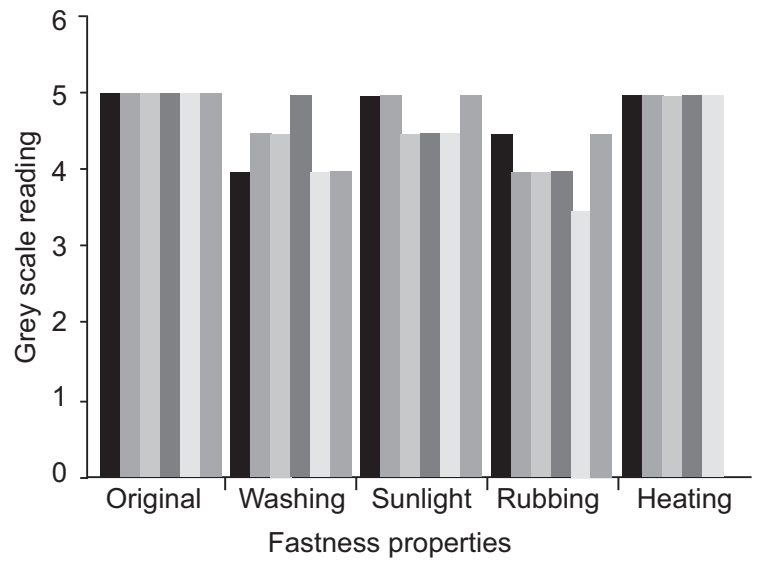

$\square$ Z. jujube $\square$ A. lebbeck $\square$ C. dichotoma $\square$ F. benghalensis F. benghalensis2 C. fistula

Fig. 4. Fastness properties of Z. jujube, A. lebbeck, C. dichotomy, F. benghalensis, $F$. benghalensis(2) and C. fistula with $\mathrm{KMnO}_{4}$ mordant.

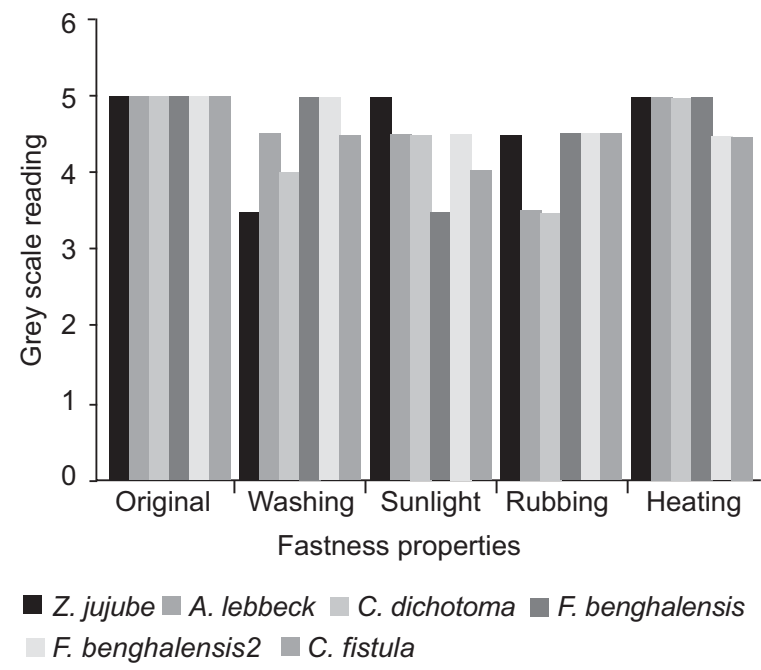

Fig.5. Fastness properties of Z.jujube, A. lebbeck, C. dichotomy, F. benghalensis, $F$. benghalensis(2) and C. fistula with potash alum mordant. 
helpful to generate employment, safe for ecology (Mahanta and Tiwari, 2005), provide economic benefits through sustainable yield and harvest of dye bearing plants (Saravanan et al., 2014). On the other side, commercialization of natural dye can help to boost up the economy of the country (Belemkar and Ramachandran, 2015; Saravanan et al., 2014; Upadhyay and Choudhary, 2014; Ghorpade et al., 2000) which has an opportunity to earn carbon credits by reducing consumption of petroleum based synthetic dyes (Aishwarya, 2014).

In present study plant bark is used for the extraction of dye which is considered as wasted part of plant and is easily available. The use of bark did not lead the threat or extinction of plant, while in other study $H$. mutabilis flower used for extracting natural dyes and applied on silk fabric (Rakhi and Padma, 2005). Flower is an important part of plant and first source for the production of new plant. They used cotton rose for extraction of dye which is medicinally important and use for treatment of skin (Dasuki, 2001). Moreover, large number of flowers is required for colouring the fabric which may lead the extinction of plant. Natural dyes are preferred over synthetic dyes because of its harmless nature. So, the selection of mordants is much important in the present study $\mathrm{CuSO}_{4}, \mathrm{KMnO}_{4}, \mathrm{FeSO}_{4}$ and Pot-Alum used as mordant. These mordants are non-toxic and easily degradable, while in other study $F$. religiosa L. bark was used for the extraction of dye and applied on silk fabric (Saravanan and Chandramohan, 2011) but they used stannous chloride as mordant which is responsible for human DNA damaging because it quickly receive by white blood cells of human being (Mclean et al., 1983).

After dyeing the evaluation of fastness properties (washing, heating, rubbing and sunlight) was also very important part of the this study. These properties were checked by gray scale. All the fabric with or without mordant showed the properties between good to excellent while in other study mangrove bark is used to form natural dyes and applied on silk fabric (Nattaya et al., 2013). They used stannous chloride as mordant which showed very poor light fastness property on silk fabric and ferrous sulphate showed poor washing property (Pervaiz et al., 2016 a, b and c).

\section{Conclusion}

This study concluded that natural dyes extracted from bark of Z. jujube, A. lebbeck, C. dichotomy, C. fistula,
$F$. benghalensis and the root of $F$. benghalensis can be successfully applied on silk in the presence of four mordants $\left(\mathrm{CuSO}_{4}, \mathrm{KMnO}_{4}, \mathrm{FeSO}_{4}\right.$ and Pot- Alum). Almost 30 different shades can be produced from the same extract. The mordant treated dyes have good colours and wash fastness. The strength properties of all extracted dyes range between 3 to 5 , shown by C. fistula. The highest fastness property which range is in 4 to 5 . It can also be concluded that natural dyes are found environment friendly, low cost, non-carcinogenic, non-hazardous and very useful for silk dyeing. The results of silk dyeing with natural dyes by using different mordants were found encouraging in terms of their colour fastness to light, heat, rubbing and washing properties. Therefore, there is a good scope for Pakistan's silk industry to use natural dyes to meet the fundamental requirement of European Union, to earn carbon credits by reducing the use of synthetic dyes and to improve the socio-economic condition of farmers by yielding and harvesting dye bearing plants. Therefore, the role of the government should be to encourage the use of natural dyes by providing soft loans and financial support to farmers for the cultivation of dye bearing plants. In addition, government can provide assistance in marketing of natural dyes and reward the environment friendly silk industries.

Conflict of Interest. The authors declare no conflict of interest.

\section{References}

Aishwarya, A.D. 2014. Extraction of natural dyes from fungus-An alternate for textile dyeing. Journal of Natural Sciences Research, 4: 1-6.

Allen, M.W., Bain, G. 2008. Measuring the UV Protection Factor of Fabric. Varian Australia Pty Ltd.

Bechtold, T., Mahmud, A.A., Komboonchoo, S. 2009. Sustainable dyes from agrifood chain co-products. In: Total Food. Walden, K.W., Moates, G.K., Faulds, C.B. (eds.) RSC Publishing, pp. 211-218. Cambridge.

Belemkar, S., Ramachandran, M. 2015. Recent trends in Indian textile industry-exploring novel natural dye products and resources. International Journal on Textile Engineering and Processes, 1: 33-41.

Chenghaih, B., Mallikarjuna, K., Mahesh, K., Alagusundaram, M., Madhusudhana, C. 2011. Studies on synthesis and anti-inflammatory activity 
of reduced spiff bases of phenylalanine derivatives. International Journal of Periodontics and Restorative Dentistory, pp. 516-126.

Dasuki, U.A. 2001. Hibiscus. In: Plant, van Valkenburg, J.L.C.H., Bunyapraphatsara, N. (eds).

DivyaLekshmi, R.B., Ravi, D. 2013. Extraction of natural dyes from selected plant sources and its application in fabrics. International Journal of Textile and Fashion Technology, 3: 53-60.

Fan, Y., Zhao, Y., Liu, A., Hamilton, A., Wang, C., Li, L., Yang, L. 2018. Indigenous knowledge of dyeyielding plants among Bai communities in Dali, Northwest Yunnan, China. Journal of Ethnobiology and Ethnomedicine, 14: 1-11.

Geng, Y., Zhang, Y., Ranjitkar, S., Huai, H., Wang, Y. 2016. Traditional knowledge and its transmission of wild edibles used by the Naxi in Baidi Village, northwest Yunnan Province. Journal of Ethnobiology and Ethnomedicine, 12: 1-21.

Ghorpade, B., Darvekar, M., Vankar, P.S. 2000. Ecofriendly cotton dyeing with sappan wood dye using ultrasound energy. Colourage, 47: 27-30.

Han, S., Yang, Y. 2005. Antimicrobial activity of wool fabric treated with curcumin. Dyes and Pigments, 64: 157-161.

Hwang, E.K., Lee, Y.H., Kim, H.D. 2008. Dyeing, fastness and deodorizing properties of cotton, silk, and wool fabrics dyed with gardenia, coffee sludge, Cassiatora L., and pomegranate extracts. Fibers and Polymers, 9: 334-340.

Jadhao, N.U., Rathod, S.P. 2013. The extraction process and antioxidant properties of patuletin dye from wasted temple French marigold flower. Asian Journal of Plant Science and Research, 3: 127132.

Khan, M.I., Ahmad, A., Khan, S.A., Yusuf, M., Shahid, M., Manzoorand, N., Mohammad, F. 2011. Assessment of antimicrobial activity of catechu and its dyed substrate. Journal of Clean Production, 19: 1385-1394.

Kulkarni, S.S., Gokhale, A.V., Bodake, U.M., Pathade, G.R. 2011. Cotton dyeing with natural dye extracted from Pomegranate (Punicagranatum) peel. Universal Journal of Environmental Research \& Technology, 1: 135-139.

Kumar, V., Prabha, R. 2018. Extraction and analysis of natural dye. Journal of Natural Products and Plant Resources, 8: 32-38.

Kumaresan, M., Palanisamy, P.N., Kumar, P.E. 2011. Application of eco-friendly natural dye obtained fromflower of Spathodeacampanulata on silk using combination of mordants. European Journal of Scientific Research, 52: 306-312.

Mahanta, D., Tiwari, S.C. 2005. Natural dye-yielding plants and indigenous knowledge on dye preparation in Arunachal Pradesh, northeast India. Current Science, 88: 1474-1480.

Mclean, J.R., Birnboim, H.C., Pontefact, R., Kaplan, G.J. 1983. Chemico Biological Interactions, 46: 189-200.

Mongkholrattanasit, R., Wongphakdee, W., Sirikasemlert, C. 2007. Dyeing and colour fastness properties of silk and cotton fabrics dyed with eucalyptus bark extract. RMUTP Research Journal, 1: 41-49.

Mujadžiæ, S., Oros, D., Kracher, D., Pankiewicz, N., Reziæ, I., Reziæ, T., Haltrich, D., Ludwig, R. 2014. Systematic degradation of synthetic dyes with heme and flavin containing oxido reductases. Busse Collection, 99: 1055-1057.

Nattaya, P., Monthon, N., Buppha, N.S., Narumolband, R.N., Rattanaphol, M. 2013. Silk fabric dyeing with natural dye from mangrove bark (Rhizophoraapiculata Blume). Extract, 49: 122129.

Onal, A., Sari, A., Soylak, M. 2005. Ellagic acid from gallnut (Quercusinfectoria): extraction and determination of its dyeing conditions for natural fibres. Journal of Scientific and Industrial Research, 64: 491-495.

Paitoon, A., Supawadee, S., Worawit, P., Sorasak, L., Suree, P. 2002. Production of red pigment from the root of Morinda angustifolia Roxb. Var. Scabridula craib by root cell culture. Chiang Mai University Journal of Natural Sciences, 1: 66-78.

Pervaiz, S., Mughal, A.T., Khan, Z.F. 2016a. Green fashion colours: a potential value for Punjab leather industry to promote sustainable development. Pakistan Journal of Contemporary Sciences, 1: 28-36.

Pervaiz, S., Mughal, A.T., Najeebullah, M., Khan, Z.F. 2016b. Extraction of natural dye from Rosa damascena Miller: A cost effective approach for leather dyeing. International Journal of Biosciences, 8: $83-92$.

Pervaiz, S., Mughal, T.A., Khan, F.Z. 2016c. Leather dyeing with plants dyes: a review. Journal of Biodiversity and Environmental Sciences (JBES), 9: 455-464

Plácido, J., Chanagá, X., Ortiz-Monsalve, S., Yepes, M., Mora, A. 2016. Degradation and detoxification 
of synthetic dyes and textile industry effluents by newly isolated Leptosphaerulina $\mathrm{Sp}$. from Colombia. Journal of Photochemistry and Photobiology B: Biology, 3: 1-14.

Rakhi, S., Padma, S.V. 2005. Dyeing cotton, wool and silk with Hibiscus mutabilis (Gulzuba). Dyes and Pigments, 74: 464-469.

Ranjit, A.J.A., Kalirajan, K. 2012. Antifungal activity of different natural dyes against traditional products affected fungal pathogens. Asian Pacific Journal of Tropical Biomedicine, 12: 60438-60439.

Sachan, K., Kapoor, V.P. 2007. Optimization of extraction and dyeing conditions for traditional turmeric dye. International Journal of Traditional Knowledge, 6: 270-278.

Samantaa, A.K., Agarwal, P. 2009. Application on natural dyes on textiles. Indian Journal of Fibre and Textile Research, 34: 384-399.

Saravanan, P., Chandramohan, G., Mariajancyrani, J., Kiruthikajothi, K. 2014. Eco-friendly dyeing of cotton fabric with a natural dye extracted from flowers of Lantana camara Linn. International Journal of Bioasays, 3: 1653-1656.

Saravanan, P., Chandramohan, G. 2011. Dyeing of silk with eco-friendly natural dye obtained from barks of Ficus religiosa L. University Journal of Environment Research and Technology, 3: 268-273.

Shadeera, R.N.M. 2015. Removal of harmful textile dye congo red from aqueous solution using chitosan and chitosan beads modified with CTAB. International Journal of Engineering Science, 5: 75-82.

Shahid, M., Mohammad, F. 2013. Recent advancements in natural dye applications: a review. Journal of Cleaner Production, 53: 310-331.

Shakeri, A., Soheili, V., Karimi, M., Hosseininia, S.A.,
FazlyBazzaz, B.S.M. 2018. Biological activities of three natural plant pigments and their health benefits. Journal of Food Measurement and Characterization, 12: 356-361.

Singh, R., Jain, A., Panwar, S., Gupta, D., Khare, S.K. 2005. Antimicrobial activity of some natural dyes. Dyes and Pigments, 66: 99-102.

Siva, R. 2007. Status of natural dyes and dye-yielding plants in India. Current Sciences, 92: 916-925.

Sivakuma, V., Vijaeeswarri, J., Lakshmi, A.J. 2011. Effective natural dye extraction from different plant materials using ultrasound. Industrial Crops and Products, 33: 116-122.

Srivastava, S.K., Gautam, R.P. 2014. Inventorisation and documentation of dye yielding plant diversity of Eastern Uttar Pradesh. International Journal of Research in Engineering and Bioscience, 2: 7075 .

Thiyagarajan, S., Balakrishnan, K., Tamilarasi, S. 2015. A study of extraction and dyeing behaviour of natural dye obtained from cotton: a study. IOSR Journal of Applied Chemistry, 8: 85-89.

Upadhyay, R., Choudhary, M.S. 2014. Tree barks as a source of natural dyes from the forests of Madhya Pradesh. Global Journal of Bioscience and Biotechnology, 3: 97-99.

Vankar, P.S., Shankar, R.,Wijayapala, S. 2009. Dyeing cotton, silk and wool yarn with extract of Garniciamangostana pericarp. Journal of Textile and Apparal, Technology and Managment, 6: 110.

Vanker, P.S., Shanker, R., Verma, A. 2007. Enzymatic natural dyeing of cotton and silk fabrics without metal mordants. Cleaner Production, 15: 14411450 . 